\title{
A Rock Physics based Petroleum Reservoir Characterization. The Case of a West African Reservoir
}

\author{
Mukhtar Habib ${ }^{\star}$ A.D.Bida and Abubakar Bello \\ Department of Mineral and Petroleum Resources Engineering, Kaduna Polyechnic, Nigeria
}

\section{Article Info}

\section{*Corresponding author: Mukhtar Habib, PhD \\ Department of Mineral and Petroleum \\ Resources Engineering \\ Kaduna Polyechnic, Nigeria \\ E-mail: mukhtarhabib102@gmail.com}

Received: September 28, 2018
Accepted: November 29, 2018
Published: December 4, 2018

Citation: Habib $M$, Bida AD, Bello A. A Rock Physics based Petroleum Reservoir Characterization. The Case of a West African Reservoir. Int J Petrochem Res. 2018; 2(3): 207-211.

doi: 10.18689/ijpr-1000137

Copyright: ( 2018 The Author(s). This work is licensed under a Creative Commons Attribution 4.0 International License, which permits unrestricted use, distribution, and reproduction in any medium, provided the original work is properly cited.

Published by Madridge Publishers

\begin{abstract}
The primary variables that determine the elastic response in clastic sediments are porosity, minerology and pore fluid. However typically, only two are obtained from seismic data. As a result, resolving petroleum and gas reservoir properties in respect of seismic data is not obtainable. In order to resolve this problem a case study is presented here. The study is based on well log data derived from the West African Congo basin. A marine environment characterized by thick shale above a shaly/sand oil layer with elastic properties linked to sediment properties by the rock-physics model of Han et al. (1986). Taking into consideration the work of Thomas and Stieber (1975), a petrophysical linear link was developed based on conceptual inferences. This link is expected to serve as a means of substituting porosity for clay content and vice versa in order to resolve the underdetermined system of rock-physics equations. As a result, an inversion of reservoir elastic properties for petrophysical properties becomes obtainable. Furthermore, this work presents reservoir delineation based on Han et al (1986) model on the well log scale and later up scaled to the seismic scale.
\end{abstract}

Keywords: Han et al. (1986); Porosity; Clay content; Reservoir

\section{Introduction}

Making best management decisions in any oil and gas field development program is no doubt a function of a clearly defined and qualitative reservoir characterization. It is a common knowledge that the decision to go ahead with any such project is based on economically viable pay zone. The importance of a coherent static model in the overall reliability of reservoir management has been constantly emphasized. Several author's [1-6], have established that the static characterization of reservoirs both in terms of geometry and petrophysical properties are key factors for reservoir performance. It is worth stating here that in many cases static model is been matched with reservoir performance history in a move to measure the accuracy of the geologic models. Therefore, the result of reservoir characterization defines whether to continue with well completion or not. This important decision is made at the middle of financial investment during the project. The decision is even more critical when one is dealing with several wells or an entire field.

Petrophysical analysis forms a bedrock of reservoir characterization in which data such as well logs, special core analysis (SCAL), mud logging and other sources are analyzed and interpreted for the purpose of establishing models that could effectively represent lithology, clay content $(C)$, porosity $(\phi)$, Saturation $\left(S_{w}\right)$, permeability $(K)$, production rate and economic evaluation that are targeted on a zone of interest [7-9]. Rock physics on the other hand, makes use of petrophysical data and other core observations data in order to provide alternative elastic properties of the same formation 
under study. These properties are of great importance for an improved reservoir characterization and modeling, because it deals with the theoretical and experimental study of the physical properties of rocks, their relationships, and their expression in geophysical and petrophysical data. Rock Physics is currently playing an important role in optimizing reservoir performance as well as management, due to its ability to give explicit information when compared to petrophysical analysis result, thereby giving strategic advantage for evaluating rock properties and there changes under reservoir conditions from insitu measured data. Furthermore, it establishes a relationship between material properties and seismic response so that properties can be observed seismically, and its key advantage is its ability to translate basic rock properties into elastic properties (forward modeling) and otherwise (inversion/backward modeling), for the purpose of exploration, exploitation and management of petroleum and gas reservoirs.

Rock physics have a variety of models in application as presented in some publications [10,11]. As a category model, empirical models are built on some basic assumptions which are applied to determine some co-efficients by calibrating a regression data. Some of the best known models are Han's regression [12] for Velocity $(V), C$ and $\phi$ in sand stone reservoirs, the [13] for $V_{p}$-Density $(\rho)$ relations and the [14] for $V_{p} / V_{s}$ relations.

Various reservoir prediction models have been proposed by several authors, the common forward models utilized are on the basis of statistical analysis which work better when computing elastic properties if $\varphi$ and $C$ are known [12,15-16]. For this category of models, a noteworthy match between [12] model and the data utilized for this study was observed during the rock physics diagnostic [12] et al. derived some equations that provide a significant contribution in finding other possible reasons for velocity reduction. The equations were derived by means of statistical methods using 75 different brine saturated sandstone samples with porosity ranging from 3 to $30 \%$ and clay volume ranging from 0 to $55 \%$. These equations, which relate velocities ( $\mathrm{P}$ and $\mathrm{S}$ waves) to total porosity and clay content, revealed that sonic velocity, get reduced with an increase in the amount of clay volume. Another contribution is the possibility of obtaining elastic properties when the values of porosity, clay content and confining pressure are known. Inversely, clay content can be obtained if $\mathrm{P}$ wave velocity, porosity and confining pressure are known.

Seismic inversion has been playing an important role in mapping elastic properties, such as the Poisson's ratio $(v)$, P-wave impedance $\left(I_{p}\right)$, and density $(\rho)$, in the subsurface. The target is always toward evaluating reservoir petrophysical properties such as porosity $(\varphi)$, clay content $(C)$, and pore fluid (Sw). The conversion of these elastic properties into petrophysical properties requires a rock physics model that links $I_{p}$ and $v$ to $\varphi, C$, and Sw. However, even if a perfect rock physics model is available, we cannot resolve two equations for three unknowns. The problem is that no more than two elastic properties can be obtained from seismic data.
In this paper, we (1) established a petrophysical linear relationship between porosity and clay content based on the [12] empirical relation thereby enabling a substitution between porosity and clay content (2) Conducted reservoir delineation on the basis of data derived from Han's model as a move to optimize petroleum reservoir characterization through rock physics approach.

\section{Methodology}

Two reservoir petrophysical properties $(\phi$ and $C$ ) and two reservoir elastic properties; acoustic impedance $\left(I_{p}\right)$ and poisson ratio $(v)$ were the primary parameters considered herein, because understanding of $\phi$ and $C$ is required for a shaly sand reservoir. The workflow starts from (1) well log quality control (QC) and conditioning to ensure that the required data were available and physically reasonable in support of Petrophysics and Rock physics activities; (2) Petrophysical analysis was conducted in order to generate important log curves, such as $\phi, C, \rho$ and resistivity of the study interval, this enables definition of facies intervals with respect to depth; (3) Based on conditioned well logs (measured $V_{p}, V_{s}$ and $\rho$ ), Rock physics (elastic) properties such as $I_{p}$ and $v$ were computed and fluid substitution was performed through [17] equations so as to bring all data to $100 \%$ brine. Then a rock physics diagnostics was performed by cross-plotting $I_{p}$ and $v$ versus $\phi$. The idea here was to select a model that match the well log data. A model based clay content was generated from the selected [12] model (4) Reservoir rock portion was delineated on the bases of $I_{p}$ and $v$ crossplot color coded by porosity log derived from the [12] model (5) A petrophysical linear link between Porosity $\phi$ and model based $C$ was established.

\section{Result: Case Study Application (Well Log and Seismic)}

This study is based on well log data derived from the West African Congo basin. A marine environment characterized by thick shale above a shaly/sand oil layer. The Miocene target reservoir is a series of turbidite sediments deposited on a broader valley, its upper part consists of homogeneous sandy deposits (figure 1 in interval 2912 2931m), followed by prograding shaly deposits. The lower part is the turbidite deposit composed of sandy deposits with intercalated shaley layers figure 1 in interval 2997 3098 m).

\section{Step 1: Data gathering, quality check, editing and conditioning}

Here, initial well data (density, compressional and shear velocities logs, etc.) with spurious values were corrected by the help of rock physics modeling.

\section{Step 2: Petrophysical analysis}

Porosities of the reservoir sands range from $15 \%$ to $30 \%$ and get reduced with an increased amount of clay content, thereby causing a velocity reduction (Figure 1). This observation was an important clue by assuming that the only minerals within the study area are quartz and clay. 
A lithology indicator ( $G R$ log) was utilized to derive shale volume and clay content. This is done by linearly scaling $G R$ in order to put forward a maximum and minimum $C$ that corresponds to the $G R$, in which a $C$ value of 0.07 for minimum $G R$ (pure sand) and 0.93 for maximum $G R$ (pure shale) were assumed. Total porosity log is not neutral in the proposed methodology since it must be computed from density log, according to Equation (1). The equation is based on the assumption that density of the mineral phase is fixed as 2.65 $\mathrm{g} / \mathrm{cm}^{3}$ while bulk density is based on brine saturated conditions.

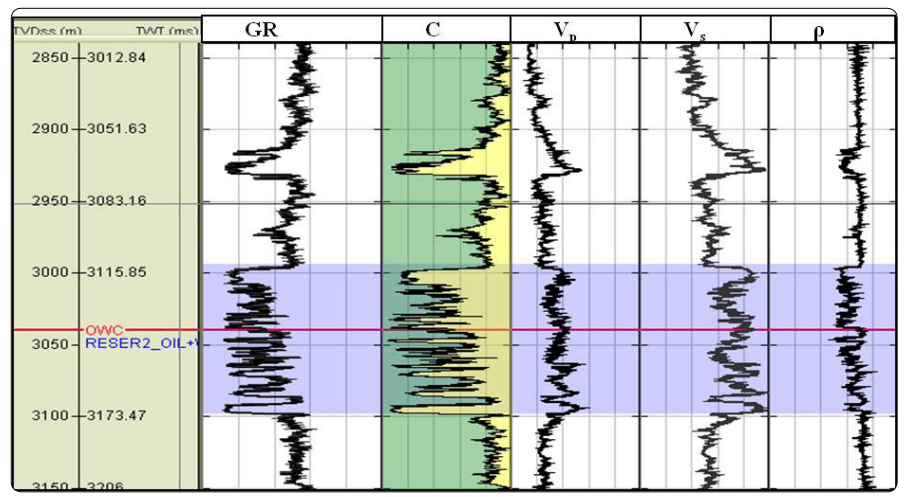

Figure 1. Well log curve applied for this study. From left to right: Gamma ray, clay content, P-Velocity, S-velocity and density.

$\phi=\frac{2.65-\rho_{b}}{2.65-\rho_{w}}$

$\rho_{b}=(1-\phi) \rho_{b}+\phi \rho_{f}$

where $\rho_{b}$ is the bulk density, $\rho_{w}$ is the density of brine given in Table 1. $\rho_{s}$ and $\rho_{f}$ are densities of mineral and fluid phase respectively.

\section{Step 3: Rock physics diagnostics and modeling}

This step comprise of rock physics diagnostics which consist of trying several rock physics models in order to determine the one that best fit the data. Since majority of rock physics models were derived from brine saturated rocks, the actual original oil bearing reservoir were replaced by $100 \%$ brine through Gassmann equations [12]. Model curves for $I_{p}$ and $v$ have been calculated for different values of $C_{\text {, }}$ which was found to match the data as depicted in figure 2 (left and right). On $I_{p}$ or $v$ versus total porosity crossplot overlain by Han's model at different values of $C$, there is a noteworthy correspondence between Han's model and the data (Figure 2). It is therefore clear that both $\phi$ and $C$ significantly affected $I_{p}$. It can also be seen from figure 2 (left), that at a constant $C_{1} I_{p}$ increases with a decrease in $\phi$. Conversely, at a constant $\phi, C$ decreases with an increase in $I_{p}$. This dependence property of $V_{p}$ and $I_{p}$ on $C$ was carefully presented by $[12,16]$. In figure 2 (right), value of $v$ calculated at $100 \%$ water saturation was presented, so as to serve the purpose of understanding the dependence of $v$ on $\phi$ and $C$ and/or lithology. It can be seen that both $\phi$ and $C$ significantly affect $v_{\text {, }}$ it can also be observed that at a constant $C$, an increase in $v$ corresponds to an increase in $\phi$, while at a constant $\phi$ a large value of $C$ also represents a large value of $v$. The dependence of $v$ on $\phi$ is always clear in sand and shaly formations. It is apparent that this dependence is strongly linked to lithology because $\phi$ and lithology vary together. The yellow rectangle on figure 2 depicts the limits of the target reservoir which is also colored in yellow on the GR curve shown in the (Figure 2). A close look of this figure reveals a $C$ range of 0 to 0.55 for reservoir sand and that of the overburden shale at 0.45 to 0.95 .

Han's model was selected for this study because the model was derived from empirical data for brine saturated consolidated sediments. While the diagnostics conducted above reveal that the model matches the data from our study area, meaning that it is consistent with the geological background of the study interval. This makes the model predictive beyond the data set used for matching. Han's model is a strong tool and a simple means of manipulating porosity and lithology as well as elastic wave velocity. The models were generated from a huge set of well log and core data, which provides relative degree of certainty that the models are efficient and can be utilized on other sets of data whose original backgrounds are analogous. Other simple empirical equations applicable for similar case are that of $[18,19]$. But due to the fact that Han's model suitably describes and explains our data, it has been decided to apply it for getting the model based clay content.

Considering a confining pressure of $20 \mathrm{MPa}$, with velocities in $\mathrm{km} / \mathrm{s}$ and sandstone samples are water charged, Han's equations applied herein are written as follows,

$V_{p}=5.49-6.94 \phi-2.17 C$

$V_{s}=3.39-4.73 \phi-1.81 C$

Where $V_{p}$ and $V_{s}$ are compressional and shear wave velocities respectively.

$I_{p}$ and $v$ as functions of $V_{p}, V_{s}$ and $\rho_{b}$ are expressed in Equations. $3,4,5$ and 6 as follows;

$I_{p}=\rho_{b} V_{p}$

$v=\frac{1}{2} \frac{V_{p}^{2} / V_{s}^{2}-2}{V_{p}^{2} / V_{s}^{2}-1}$

The idea is to get a model based $C$ from initial $V_{p}$ and $V_{s}$ logs by applying the model-based approach. Hence, any of Equations 3 or 4 can be applied.

The comparison between $C$ derived from linearly scaled $G R \log$ (black) with the model-based $C$ curve (red) is depicted in Figure 3 (second panel), in which a similar trend is observed between the two. Meanwhile, the model-based $C$ is used in the remaining part of this research.

The model based clay content $(C)$ was preferred over the clay content derived from linearly scaled gamma ray. The choice of model based $C$ is explained by the fact that it is linked to elastic properties $\left(V_{p}\right.$ and $\left.V_{s}\right)$ through rock physics model of [12].

It is important to mention that during this step, several rock physics models were tested [12]. Models was found to better describe and explain the real data. Indeed, except some points, all the points representing the data fall nearly within 
the boundaries imposed by Han's model. In addition, it is clear that P-wave impedance gets reduced with an increase in the amount of clay volume, while the $v$ decreases with a decreasing amount of clay volumes. This observation was also made by [12].

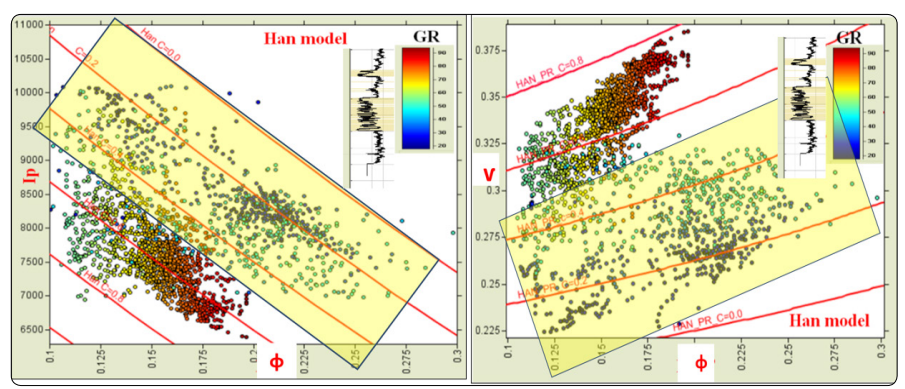

Figure 2. Cross-plot of Porosity versus P-impedance (left) and Poisson ratio (right) color-coded by Gamma ray. The overlain red lines are Han's models with different percentage of clay volumes.

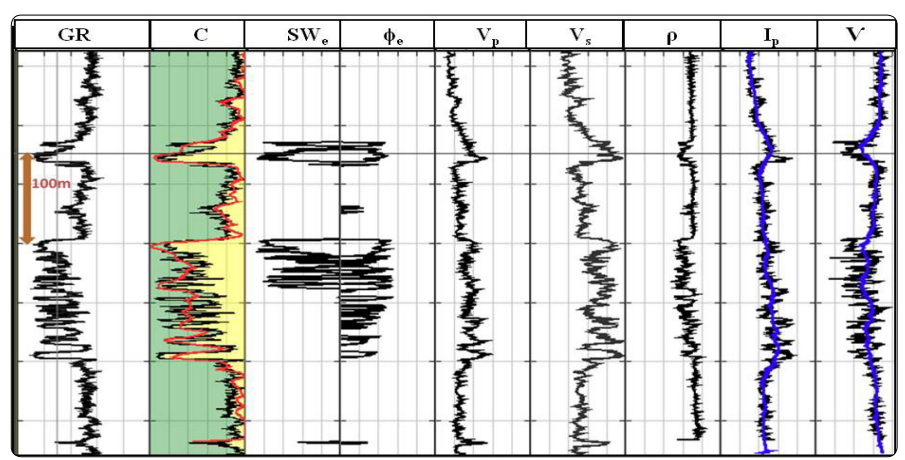

Figure 3. Well log curve applied for this study. From left to right:

Gamma ray, clay content, effective water saturation, effective porosity, P-Velocity, S-velocity, density, P-impedance and Poisson's ratio. In the second frame, the black curve comes from linearly scaled gamma ray curve while the red curve is calculated as to match Han's (1986) model predictions.

\section{Step 4: Petrophysical link between $\phi$ and $C$}

The concept proposed by [20] was applied here in order to establish the desired link. (Figure 4) shows the cross-plot of $\phi$ versus the model based $C$ in which it can be observed that $\phi$ is relatively large but experiences a decrease as the value of $C$ increases in the clean sand. This trend shows a turning point at $C=0.5$, where the transition from sand to shale occurs thereby making a $\mathrm{V}$-shaped pattern. This $\mathrm{V}$-shape pattern is a characteristic of a bimodal sand/shaly mixture [15,21].

Following the works of, the relationship between Porosity and model based clay content was established using two linear equations.

From the actual $\phi-C$ cross plot, the trend within the sand reservoir is not well defined, while in the shale zone, the trend is quite clear. This observation revealed that for a shaly sand reservoir zone, several trends are possible. As a result, several trends in terms of linear equations can be tested in the shaly sand zone during $\phi-C$ any possible inversion. Therefore, through substitution method, Equations 7 and 8 , can be applied to optimize result and will no doubt be applicable in inverting $\phi$ and $C$ from $I_{p}$ on log scale and on seismic scale as well.

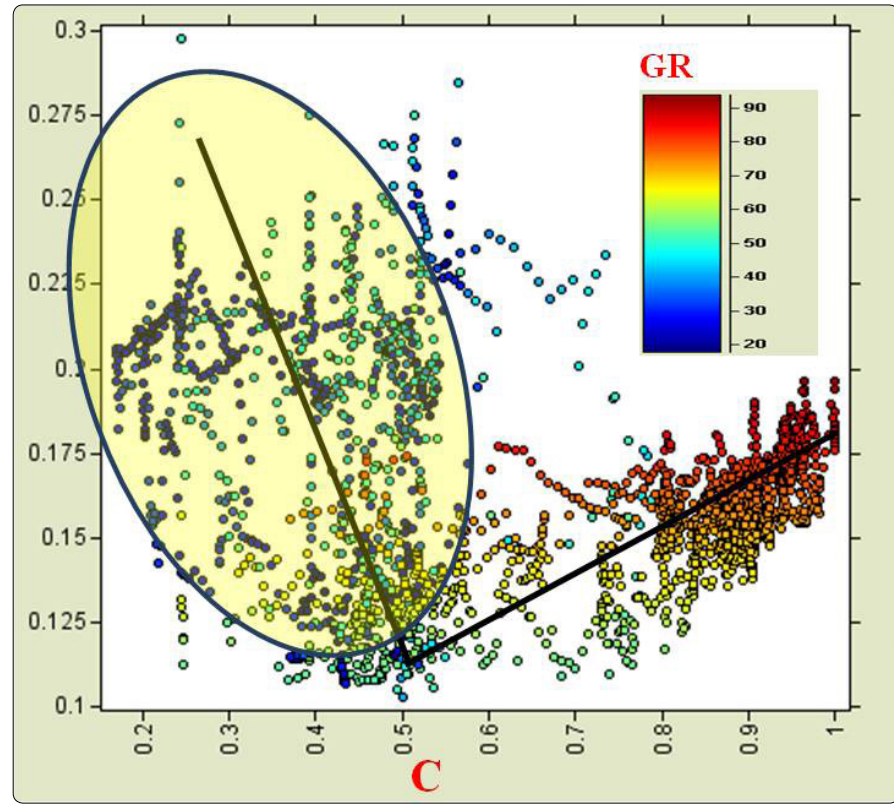

Figure 4. Porosity as a function of clay content. Straight lines are in accordance with Equations (7) and (8). The circled part represent the reservoir.

$C<0.5 ; \phi=0.188-0.0871 C$

$C \geq 0.5 ; \phi=0.296-0.327 C$

\section{Step 5: Reservoir delineation by combining $v$ and $I_{p}$}

Second contribution of this work is presented in this section. The essence of this step is to make reservoir delineation based of the rock physics diagnostics provided by [12] in step 3 above. This is to isolate the reservoir from the non-reservoir intervals by mapping two different domains (shale and sand). As presented by figure 2, the shale domain is having a $C$ range of $0.45-0.95$ which corresponds to a $\phi$ range of $0.1-0.125$ (Figure 5). Similarly, for the sand domain, a $C$ range of $0.0-0.55$ and a $\phi$ range of $0.125-0.22$ was mapped. The pay sand and shale zones do not overlap, which means that the sand can be traced by seismic data through combining $I_{p}$ and $v$. In order to make a clear demarcation, a cut offline that would separate the shale zone from that of the sand was developed as shown in (Figure 5). Eventually, Equation 9 was applied in respect of demarcation.

$I_{p}=350.8 v-2661.4$

If $I_{p}<3550.75 v-2661.45$, the zone is considered as sand and if $I_{p} \geq 3550.75 v-2661.45$, the zone is considered a shale zone. This Cut-off value is apparently valid with log data. Is this cutoff value going to be the same on a seismic scale? To answer this question, a cross plot of an upscaled $I_{p}$ and $v$ logs was carried out, in which similar trend with the well log scale model is observable. This has shown that the chosen cut off value is valid for reservoir delineation (Figure 6).

Reservoir delineated at the seismic scale, is slightly different from the actual one derived at the well log scale. This is because the up-scaled poison ratio curve has larger lower end values compared with the well log scale curve. This is a typical up-scaling artifact when converting to seismic from well log, therefore such a consideration has to be made while interpreting results. 


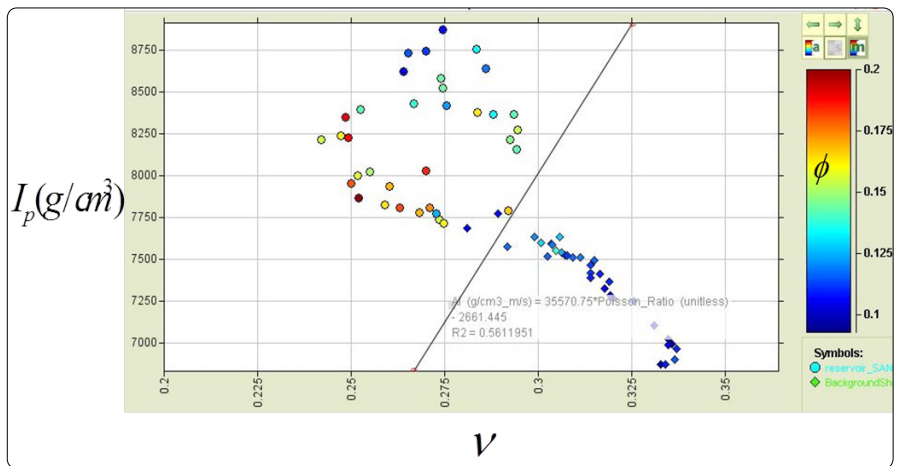

Figure 5. Well log scale delineation. P-wave impedance versus Poisson's ratio color code by porosity, with sand and shale domains mapped in accordance with equation (9)

It is therefore established that pay reservoir intervals can be detected from seismic data using a combination of seismically derived $I_{p}$ and $v_{1}$ as a result, quantification of porosity and $C$ in the sand can be attempted. For this purpose, an additional link between porosity and $C$ is required.

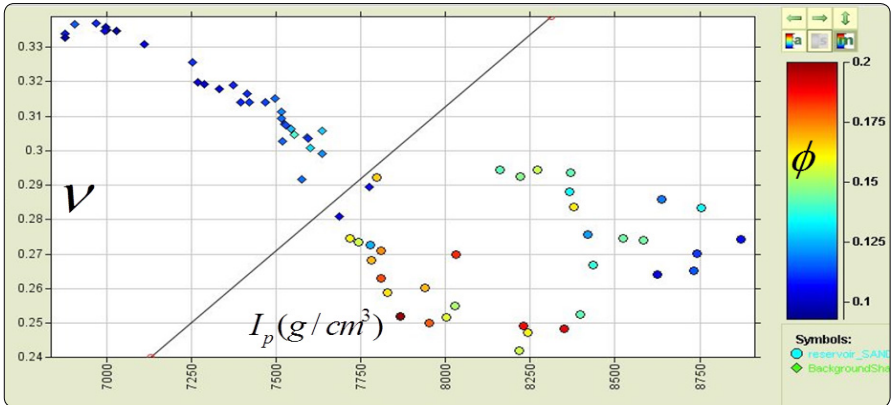

Figure 6. Seismic scale delineation. P-wave impedance versus poisson's ratio color code by porosity, with sand and shale domains separately mapped.

\section{Conclusion}

With respect to rock physics modeling of reservoir properties, Han et al. (1986) model was found to fits the data utilized herein. Han's model was used to estimate the clay content which was referred to as model based Clay content. This work also realized that model based clay content gives better results than a linear GR based clay content when computing model based acoustic impedance.

It is also presented herein that clay content derived from Han et al (1986) model gives a linear relationship with porosity thereby becoming a basis for resolving the problem of underdetermine system of rock physics equation when converting elastic properties to petrophysical properties in a shaly sand environment.

\section{References}

1. Eden AL, Fox MJ. Optimum Plan of Depletion. Society of Petroleum Engineers. 1998. doi: 10.2118/17458-MS

2. Hickman TS. A Rationale for Reservoir Management Economics. Society of Petroleum Engineers. 1995.

3. Raza SH. Data Acquisition and Analysis for Efficient Reservoir Management. Society of Petroleum Engineers. 1990. doi: 10.2118/20749-MS

4. Satter A, Varnon JE, Hoang MT. Integrated Reservoir Management. Society of Petroleum Engineers. 1994. doi: 10.2118/22350-PA

5. Thakur GC. Implementation of a Reservoir Management Program. Society of Petroleum Engineers. 1990. doi: 10.2118/20748-MS

6. Wiggins ML, Startzman RA. An Approach to Reservoir Management. Society of Petroleum Engineers. 1990. doi: 10.2118/20747-MS

7. Al-Harbi WA, Labban MM, Husain K, Zahdan GO, Rihabe S, Al-Mushrifi OM. Optimizing Petrophysics Practices Through Intelligent-Tools Integration. Society of Petroleum Engineers. 2010. doi: 10.2118/134205-MS

8. Ekpoudom OJ, Ukaonu C, Egbele E, Onyekonwu MO. Integration of Geology and Petrophysics for the Characterisation of a Sandstone Reservoir. Society of Petroleum Engineers. 2005. doi: 10.2523/98814-MS

9. Worthington PF. The Direction of Petrophysics: A Five-year Perspective. Society of Petrophysicists and Well-Log Analysts. 1991; 32(2): 6.

10. Dræge $A$, Jakobsen $M$, Johansen TA. Rock physics modelling of shale cementation. SEG Technical Program Expanded Abstracts. 2004; 17781781. doi: $10.1190 / 1.1845170$

11. Movko G, Jizba D. The Rock Physics Handbook. $1^{\text {st }}$ edition.Cambridge Press. 1991.

12. Han D, Nur A. Effects of Porosity and Clay Content on Wave Velocity of Sand stones. Geophysics. 1986; 51(11): 2093-2107. doi: 10.1190/1.1442062

13. Gardner GHF, Gardner LW, Gregory AR. Formation Velocity and DensityThe Diagnostic Basics for Statigraphic traps. Geophysics. 1974; 39(6): 770780. doi: $10.1190 / 1.1440465$

14. Castagana G. Shear-Wave Velocity Estimation In Porous Rocks: Theoretical Formulation, Preliminary Verification And Applications. Geophysic pros. 1992; 40(2): 195-209. doi: 10.1111/j.1365-2478.1992.tb00371.x

15. Marion D, Jizba D. Acoustic Properties of Carbonate Rocks: Use in Quantitative Interpretation of Sonic and Seismic Measurements. Carbonate Seismology. 1990; 75-94. doi: 10.1190/1.9781560802099.ch5

16. Tosaya C, Nur A. Effect of Digenesis and Clays on compressional Velocities in rocks. Geophysical Research Letters. 1982; 9(1): 5-8. doi: 10.1029/ GL009i001p00005

17. Gassmann F. About the elasticity Poroser media. Communications from the Institute of Geophysics. 1956; 17: 1-23.

18. Willie MRJ, Gregory AR, Gardner WL. Elastic Wave Velocities in heterogenous Porous Media. Geophysics. 1956; 21(1): 41-70. doi: 10.1190/1.1438217

19. Raymer DS, Hunt ER, Gardner JS. An Improved Sonic transit time-toPorosityTransform. 21st edition. Annual Meeting, Society of Petrophysist and Well $\log$ Analyst. 1980.

20. Thomas EC, Stieber SJ. Distribution of Shale in Sandstones and Its Effect upon Porosity. SPWLA Sixteenth Annual Logging Symposium. 1975.

21. Yale DP. Recent advances in rock physics. Geophysics. 1985; 50: 24802491. doi: 10.1190/1.1441879 